\title{
A generic framework for spatial prediction of soil variables based on regression-kriging ${ }^{\text {is }}$
}

\author{
Tomislav Hengl ${ }^{\mathrm{a}, *}$, Gerard B.M. Heuvelink ${ }^{\mathrm{b}}$, Alfred Stein ${ }^{\mathrm{a}}$ \\ ${ }^{a}$ International Institute for Geo-information Science and Earth Observation (ITC), P.O. Box 6, 7500 AA Enschede, The Netherlands \\ ${ }^{\mathrm{b}}$ Laboratory of Soil Science and Geology, Wageningen University, P.O. Box 37, 6700 AA, Wageningen, The Netherlands
}

Received 27 February 2003; received in revised form 11 July 2003; accepted 19 August 2003

\begin{abstract}
A methodological framework for spatial prediction based on regression-kriging is described and compared with ordinary kriging and plain regression. The data are first transformed using logit transformation for target variables and factor analysis for continuous predictors (auxiliary maps). The target variables are then fitted using step-wise regression and residuals interpolated using kriging. A generic visualisation method is used to simultaneously display predictions and associated uncertainty. The framework was tested using 135 profile observations from the national survey in Croatia, divided into interpolation (100) and validation sets (35). Three target variables: organic matter, $\mathrm{pH}$ in topsoil and topsoil thickness were predicted from six relief parameters and nine soil mapping units. Prediction efficiency was evaluated using the mean error and root mean square error (RMSE) of prediction at validation points. The results show that the proposed framework improves efficiency of predictions. Moreover, it ensured normality of residuals and enforced prediction values to be within the physical range of a variable. For organic matter, it achieved lower relative RMSE than ordinary kriging $(53.3 \%$ versus $66.5 \%)$. For topsoil thickness, it achieved a lower relative RMSE $(66.5 \%$ versus $83.3 \%)$ and a lower bias than ordinary kriging $(0.15$ versus $0.69 \mathrm{~cm})$. The prediction of $\mathrm{pH}$ in topsoil was difficult with all three methods. This framework can adopt both continuous and categorical soil variables in a semi-automated or automated manner. It opens a possibility to develop a bundle algorithm that can be implemented in a GIS to interpolate soil profile data from existing datasets.
\end{abstract}

(C) 2003 Elsevier B.V. All rights reserved.

Keywords: Spatial prediction; Logit transformation; Factor analysis; Visualisation; Environmental correlation

is Supplementary materials: datasets, technical note, additional results and colour graphics with animations available online at: http://www.pfos.hr/ hengl/GRK/.

* Corresponding author. AGIS centre, Faculty of Agriculture, Trg. Sv. Trojstva 3, 31000 Osijek, Croatia. Tel.: +385-31-224288; fax: +385-31-207017.

E-mail addresses: hengl@pfos.hr (T. Hengl), gerard.heuvelink@wur.nl (G.B.M. Heuvelink), stein@itc.nl (A. Stein).

\section{Introduction}

Spatial prediction is the process of estimating the values of a target quantity at unvisited locations. When applied to a whole study area, it is also referred to as spatial interpolation or mapping. Development of generic and robust spatial interpolation techniques has been of interest for quite some time (Mitas and Mitasova, 1999). In land resource inventories, kriging and its variants have been widely recognised as 
primary spatial interpolation techniques from the 1970s. In the 1990s, with the emerging of GIS and remote sensing technologies, soil surveyors became interested to use exhaustively mapped secondary variables to directly map soil variables. The first applications were based on the use of simple linear regression models between terrain attribute maps and soil parameters (Gessler et al., 1995; Moore et al., 1993). In the next phase, the predictors were extended to a set of environmental variables and remote sensing images. This approach was termed "environmental correlation" by McKenzie and Ryan (1999), or spatial prediction by multiple regression with auxiliary variables (Odeh et al., 1994, 1995). McBratney et al. (2000) coined the term CLORPT techniques. Geostatistics and the CLORPT techniques are two somewhat distinct approaches to spatial prediction and can both give satisfactory results independently one from another.

In the last decade, a number of 'hybrid' interpolation techniques, which combine kriging and use of auxiliary information, has been developed and tested. Here, two main paths can be recognised: co-kriging and kriging combined with regression (McBratney et al., 2000). The latter path was shown to be more attractive for combination of kriging and CLORPT techniques, among others because fewer model parameters need to be estimated (Knotters et al., 1995). In many cases, kriging combined with regression has proven to be superior to the plain geostatistical techniques yielding more detailed results and higher accuracy of prediction. Hudson and Wackernagel (1994) showed that kriging with use of elevation data improves mapping of temperature. Knotters et al. (1995) compared ordinary kriging with co-kriging and regression-kriging for soil mapping purposes, favouring the latter. Bourennane et al. (1996, 2000) showed that prediction of horizon thickness is more accurate with the use of a slope map as external drift. In several other studies (Odeh et al., 1994, 1995; Goovaerts, 1999b; Bishop and McBratney, 2001), combination of kriging and correlation with auxiliary data outperformed ordinary kriging, co-kriging and plain regression. Although the hybrid interpolation techniques are becoming increasingly popular, there is still a need for a generic methodology that combines theory of generalized linear models (GLM) with universal kriging.
Gotway and Stroup (1997) and Opsomer et al. (1999) give good starting points.

An (ideal) requirement for both linear regression analysis and ordinary kriging is that the target variable is normally distributed (Draper and Smith, 1998). In many soil studies, however, the variables show skewed non-normal distributions, which then reflects on residuals also. To account for the normality requirement, transformations such as logarithmic and square root are often applied prior to the regression analysis (Gobin, 2000; Gobin et al., 2001). Similarly, the log-transformation is often applied prior to kriging to account for positively skewed data. Here, the difficulties are the choice of transformation model and extreme sensitivity of errors for back-transformation (Isaaks and Srivastava, 1989). In the case of kriging combined with regression, a common problem is that the method might yield values outside the physical range (e.g. negative values) and these areas need to be manually masked or replaced (Goovaerts, 1997, p. 200). Another issue, in the case of large number of predictor maps, is the problem of multicollinearity (Neter et al., 1996, p. 285). Moreover, it is not clear whether to use all available secondary variables in prediction or only the most correlated ones (Bourennane and King, 2003). These difficulties with data emphasize a need for a generic methodology that can be used with both continuous and categorical, both normal and non-normal data.

The objective of this study was to develop a methodological framework for spatial prediction based on the theory of universal kriging. This framework can then be used with most soil profile databases in a semi-automated or automated manner. We concentrate on the integration of different data processing steps, rather than on the development of new statistical techniques. In addition, we propose an image processing technique to simultaneously visualise predictions and uncertainty associated with prediction.

\section{Methods}

\subsection{The generic framework}

By a generic framework we consider a set of robust techniques that are used jointly to transform, fit, 
interpolate and visualise the data. Here, we primarily focus on the following aspects:

- reduction of multicollinearity among predictors;

- ensuring the normality of residuals;

- exploiting the 'best' of the data, i.e. correlation with auxiliary maps and spatial dependence at the same time; and

- avoiding predictions outside the physical range.

A schematic diagram showing the generic framework is given in Fig. 1. The input variables are first transformed using logit transformation for target variables and factor analysis for continuous predictor maps. The categorical predictors are transformed to indicator maps. The target variables are then fitted using step-wise regression and residuals interpolated using kriging. The final predictions are evaluated at control points. A generic visualisation method is used to simultaneously display both prediction and uncertainty of the prediction model. Technically speaking, the developed generic framework can be termed step-wise principal component logistic regression-kriging. For practical reasons, we simply refer to it as generic framework based on regressionkriging. The development of such a framework has been announced by McBratney and Walvoort (2001). We will now first introduce the theory of universal

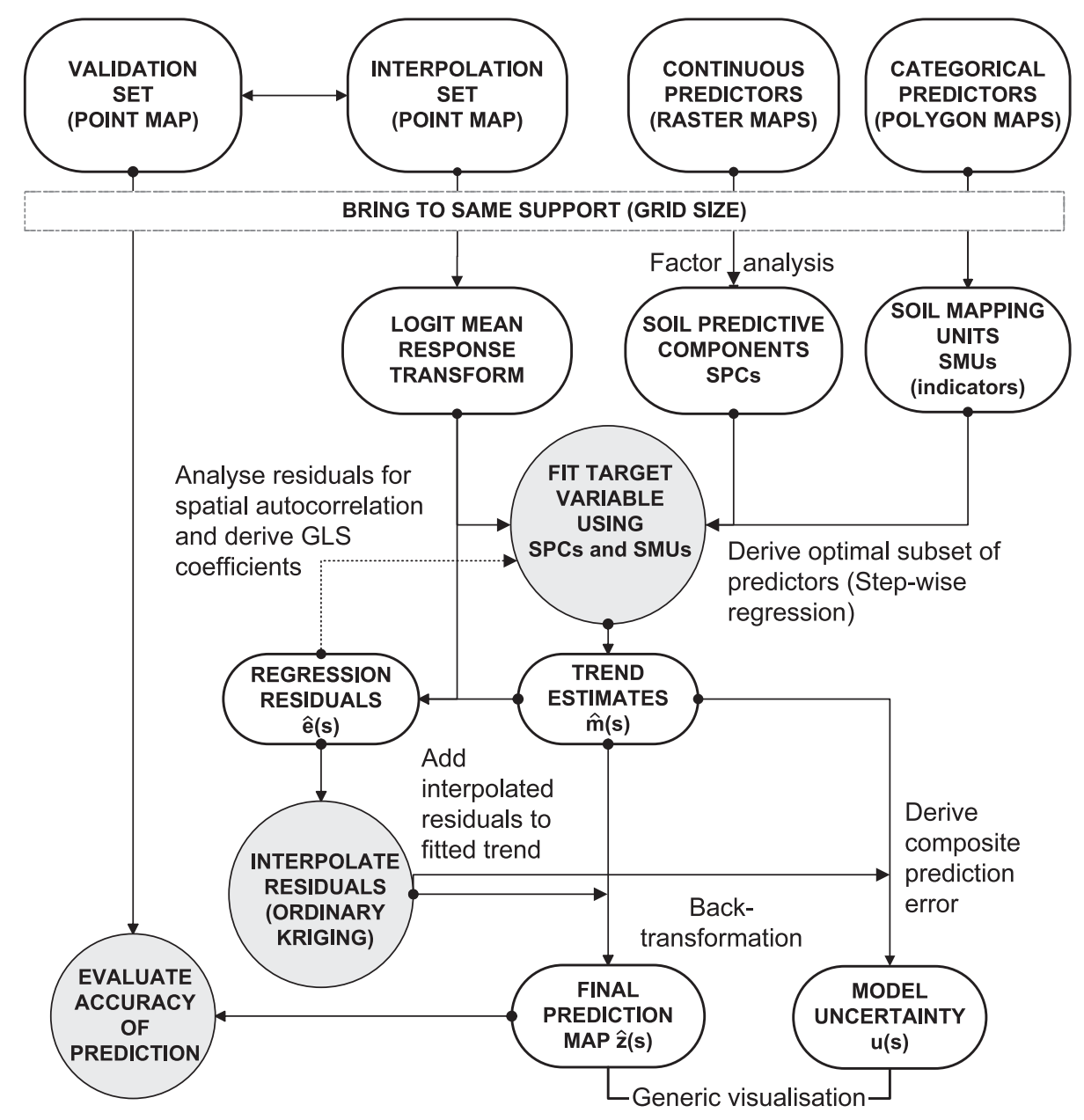

Fig. 1. Flow diagram: framework for regression-kriging (in a GIS). 
kriging and then extend its algebra using the abovedescribed framework.

\subsection{The spatial prediction technique: regression-kriging}

A spatial prediction technique, which jointly employs correlation with auxiliary maps and spatial correlation is universal kriging (UK), originally described by Matheron (1969). Many authors (Deutsch and Journel, 1992; Wackernagel, 1998), however, agree that the term Universal kriging should be reserved for the case where the drift (or trend) is modelled as a function of the coordinates only. The term Kriging with external drift (further referred to as $\mathrm{KED}$ ) is more commonly used when the drift is defined 'externally' through some auxiliary variables (Chiles and Delfiner, 1999; Wackernagel, 1998). The drift and residuals can also be fitted separately and then summed afterwards. This was originally suggested by Odeh et al. (1994, 1995), who named it "Regression-kriging" (further referred to as RK), whereas Goovaerts (1999b) uses the term "Kriging after detrending". UK, KED and RK are, in fact, equivalent methods and should, under the same assumptions, yield the same predictions (for more details, see Hengl et al., 2003b). The advantage of KED is that the equations are solved at once, while the advantage of RK is that there is no danger of instability as with the KED system Goovaerts (1997, p. 195). Moreover, RK can be more easily combined with stratification, general additive modelling (GAM) and regression trees (McBratney et al., 2000). Note that, although KED technique seems to be computationally more straightforward, it needs variogram parameters of the GLS regression residuals (which is often ignored), and therefore the GLS regression coefficients as with RK. Some authors make different assumptions and skip some computational step so that products of RK and KED might differ at the end. For example, Hudson and Wackernagel (1994), Bourennane and King (2003) make an assumption that the variogram of residuals $(e)$ is equal to the variogram of target variable $(z)$, which is a simplification. In this case, the KED prediction map will look more similar to the OK map. Other authors (Odeh et al., 1994, 1995), use only ordinary least squares estimate of the drift, which is also sub-optimal but shorter solution.
These short-cuts might be more attractive for practical applications, but are sub-optimal statistically. In further text, we will hold to the term regressionkriging instead of kriging with external drift, as it specifically implies that regression is combined with kriging.

Let the observations of soil variables be denoted as $z\left(s_{1}\right), z\left(s_{2}\right), \ldots, z\left(s_{n}\right)$, where $s_{i}=\left(x_{i}, y_{i}\right)$ is a location and $x_{i}$ and $y_{i}$ are the coordinates and $n$ is the number of observations. In the case of RK, a soil property at a new, unvisited location $\left(s_{0}\right)$ is predicted by summing the predicted drift and residuals (Odeh et al., 1994):

$\hat{z}\left(s_{0}\right)=\hat{m}\left(s_{0}\right)+\hat{e}\left(s_{0}\right)$

where the drift $\hat{m}$ is commonly fitted using linear regression analysis, and the residuals $\hat{e}$ are interpolated using ordinary kriging:

$\hat{z}\left(s_{0}\right)=\sum_{k=0}^{p} \hat{\beta}_{k} \cdot q_{k}\left(s_{0}\right)+\sum_{i=1}^{n} w_{i}\left(s_{0}\right) \cdot e\left(s_{i}\right) ;$

$q_{0}\left(s_{0}\right)=1$;

where $\hat{\beta}_{k}$ are the estimated drift model coefficients, $q_{k}\left(s_{0}\right)$ is the $k$ th external explanatory variable or predictor at location $\mathrm{s}_{0}, p$ is the number of predictors, $w_{i}\left(s_{0}\right)$ are weights determined by the covariance function and $e\left(s_{i}\right)$ are the regression residuals. In matrix notation, the RK model is:

$z=\mathbf{q}^{\mathrm{T}} \cdot \boldsymbol{\beta}+\varepsilon$

where $\varepsilon$ is the zero-mean regression residual. The predictions are made by:

$\hat{z}\left(s_{0}\right)=\mathbf{q}_{0}^{\mathrm{T}} \cdot \hat{\boldsymbol{\beta}}+\boldsymbol{\lambda}_{0}^{\mathrm{T}} \cdot \mathbf{e}$

where $\mathbf{q}_{0}$ is vector of $p+1$ predictors at $s_{0}, \hat{\boldsymbol{\beta}}$ is vector of $p+1$ estimated drift model coefficients, $\boldsymbol{\lambda}_{0}$ is vector of $n$ kriging weights and $\mathbf{e}$ is vector of $n$ residuals. The drift model coefficients are preferably solved using the generalized least squares (GLS) estimation to account for spatial correlation of residuals (Cressie, 1993, p. 166):

$\hat{\boldsymbol{\beta}}_{\mathrm{gls}}=\left(\mathbf{q}^{\mathrm{T}} \cdot \mathbf{C}^{-1} \cdot \mathbf{q}\right)^{-1} \cdot \mathbf{q}^{\mathrm{T}} \cdot \mathbf{C}^{-1} \cdot \mathbf{z}$ 
where $\mathbf{q}$ is the matrix of predictors at all observed locations $(n \times p+1), \mathbf{z}$ is the vector of sampled observations and $\mathbf{C}$ is the $n \times n$ covariance matrix of residuals:

$\mathbf{C}=\left[\begin{array}{ccc}C\left(s_{1}, s_{2}\right) & \cdots & C\left(s_{1}, s_{n}\right) \\ \vdots & \ddots & \vdots \\ C\left(s_{n}, s_{1}\right) & \cdots & C\left(s_{n}, s_{n}\right)\end{array}\right]$

The covariances between point pairs $C\left(s_{i}, s_{j}\right)$, under stationarity assumptions also written as $C(h)$, are typically estimated by modelling a variogram (Isaaks and Srivastava, 1989). A common variogram model is the exponential:

$$
\gamma(\mathbf{h})=\left\{\begin{array}{ll}
0 & \text { if }|\mathbf{h}|=0 \\
C_{0}+C_{1} \cdot\left[1-e^{-\left(\frac{\mathbf{h}}{R}\right)}\right] & \text { if }|\mathbf{h}|>0
\end{array}\right\}
$$

where $\gamma(\mathbf{h})$ is the semivariance function, which is related with the covariance function through $\gamma(h)=$ $C_{0}-C(h) . C_{0}, C_{1}$ and $R$ are variogram parameters and $|\mathbf{h}|$ is the Euclidean distance between the point pairs. Thus, RK in matrix notation is (Christensen, 1990):

$\hat{z}\left(s_{0}\right)=\mathbf{q}_{0}^{\mathrm{T}} \cdot \hat{\boldsymbol{\beta}}_{\mathrm{gls}}+\boldsymbol{\lambda}_{0}^{\mathrm{T}} \cdot\left(\mathbf{z}-\mathbf{q} \cdot \hat{\boldsymbol{\beta}}_{\mathrm{gls}}\right)$

Note that estimation of GLS residuals is an iterative process: first the drift model coefficients are estimated using ordinary least squares (OLS), then the covariance function of the residuals is estimated and used to obtain the GLS coefficients. These can be used to re-compute residuals and so on. This is the major disadvantage of using KED or RK because both the regression model parameters and variogram parameters need to be estimated simultaneously. To estimate coefficients we need the covariance function of residuals, which can only be estimated after the coefficients. In practice, a single iteration can be used as a satisfactory solution (Kitanidis, 1994), although the optimal approach is to fit these components until convergence (Opsomer et al., 1999).
The variance of the prediction error of $\mathrm{RK}$ is the UK variance (Cressie, 1993, p. 155):

$$
\begin{aligned}
\sigma_{\mathrm{E}}^{2}\left(s_{0}\right)= & \left(C_{0}+C_{1}\right)-\mathbf{c}_{0}^{\mathrm{T}} \cdot \mathbf{C}^{-1} \cdot \mathbf{c}_{0} \\
& +\left(\mathbf{q}_{0}-\mathbf{q}^{\mathrm{T}} \cdot \mathbf{C}^{-1} \cdot \mathbf{c}_{0}\right)^{\mathrm{T}} \cdot\left(\mathbf{q}^{\mathrm{T}} \cdot \mathbf{C}^{-1} \cdot \mathbf{q}\right)^{-1} \\
& \cdot\left(\mathbf{q}_{0}-\mathbf{q}^{\mathrm{T}} \cdot \mathbf{C}^{-1} \cdot \mathbf{c}_{0}\right)
\end{aligned}
$$

where $\mathbf{c}_{0}$ is the vector of covariances between residuals at the unvisited and observation locations. The first part of Eq. (9) presents the kriging variance of residuals and the second part is associated with the error of estimating the drift. The latter, in statistical terms, is equivalent to the curvature of the confidence band around the regression line (Neter et al., 1996, p. 210). Hence, the composite variance reflects the relative distance in geographical and feature space: the prediction uncertainty increases as the new predicted observation gets further away from observation points spatially and further away from the centre of the attribute or feature space.

\subsection{Transformations of soil variables}

In the case of CLORPT techniques, the functional relationship between environmental and soil variables is unknown and often very noisy (e.g. see the correlation plots by Moore et al., 1993, p. 448 and Gessler et al., 1995, p. 428). Thus, simple linear regression modelling is most commonly used to model the data. It seems, however, that a general relationship between the soil and auxiliary variables is not necessarily linear. From empirical plots drawn by Buol and Hole (1980), Jenny (1980) and Birkeland (1999, p. 142), it can bee seen that a general relationship between soil variables and the CLORPT factors is sigmoidal. This is often simply because many soil variables reach some physical minimum or maximum after a certain change of a CLORPT factor. In this situation, it is more advisable to adjust the model to the data by using some GLM transformation, rather than to adjust the data to the model Lane, 2002. To approximate such a sigmoidal shape, we used a simple logistic response function Neter et al. (1996, p. 570):

$z^{+}=\left[1+\exp \left(-\boldsymbol{\beta}^{T} \cdot \mathbf{q}\right)\right]^{-1}$ 
The key property of the logit transformation is that it can be easily linearized by transforming the target variable to a logit variable:

$z^{++}=\ln \left(\frac{z^{+}}{1-z^{+}}\right) ; \quad 0<z^{+}<1$

where $z^{+}$is the target variable standardised to the 0 to 1 range:

$z^{+}=\frac{z-z_{\min }}{z_{\max }-z_{\min }} ; \quad z_{\min }<z<z_{\max }$

and $z_{\min }$ and $z_{\max }$ are the physical minimum and maximum of $z$. This means that all new predicted values are constrained in-between these two limits.

Finally, we obtain the same RK linear Eq. (8):

$\hat{z}^{++}\left(s_{0}\right)=\mathbf{q}_{0}^{\mathrm{T}} \cdot \hat{\boldsymbol{\beta}}_{\mathrm{gls}}+\boldsymbol{\lambda}_{0}^{\mathrm{T}} \cdot\left(\mathbf{z}^{++}-\mathbf{q} \cdot \hat{\boldsymbol{\beta}}_{\mathrm{gls}}\right)$

For ratio-type or percentage-type variables (e.g. clay content, organic matter content, etc.), $z_{\min }$ and $z_{\max }$ are given by definition. In other cases, the limits need to be defined using empirical or arbitrary numbers, such as expected or sampled minimum and maximum. For example, we know that a $\mathrm{pH}$ of soil, measured in water, in some area will never be below 4 or above 9. Therefore, including these limits will prevent predictions outside the given range. Note that all $z$ values need to be different from the $z_{\min }$ and $z_{\max }$ to avoid $\ln (0)$ situations.

Another advantage of logit transformation is that it can adopt also the categorical data, which first needs to be converted to indicator variable (see later Eq. (18)). The logit transformation has already been used prior to interpolation of soil data by Triantafilis et al. (2001). Gotway and Stroup (1997) used it as a link function prior to universal kriging of a binary target variable.

The predictions are back-transformed to original scale by:

$\hat{z}\left(s_{0}\right)=\frac{e^{\hat{z}++\left(s_{0}\right)}}{1+e^{\hat{z}++\left(s_{0}\right)}} \cdot\left(z_{\max }-z_{\min }\right)+z_{\min }$

The variance of the prediction error calculated using Eq. (9), however, cannot be simply back-transformed as the error is not symmetrical around the regression plane. It can be used, though, to derive confidence limits:

$\hat{z}_{ \pm t}\left(s_{0}\right)=\frac{e^{\left[z^{++}\left(s_{0}\right) \pm t \cdot \sigma_{\mathrm{E}}^{++}\left(s_{0}\right)\right]}}{1+e^{\left[\underline{z}^{++}\left(s_{0}\right) \pm t \cdot \sigma_{\mathrm{E}}^{++}\left(s_{0}\right)\right]}} \cdot\left(z_{\max }-z_{\min }\right)+z_{\min }$

where $t$ is the threshold value of standard normal error and $\sigma_{\mathrm{E}}^{++}\left(s_{0}\right)$ is the standard deviation of the prediction error of transformed variable. From confidence limits, the probability density can be reconstructed to get an unbiased estimate of the mean and variance.

A simpler solution is to divide the prediction error of the transformed variable by the total standard deviation of observed samples. This is the normalized mean square error or relative prediction error (Park and Vlek, 2002):

$\sigma_{\mathrm{E}, r}\left(s_{0}\right)=\frac{\sigma_{\mathrm{E}}^{++}\left(s_{0}\right)}{S_{z^{++}}}$

where $S_{z^{+}}$is the standard deviation of the transformed observations:

$s_{z^{++}}=\sqrt{\frac{\sum_{i=1}^{n}\left(z_{i}^{++}-\bar{z}^{++}\right)^{2}}{n-1}}$

This estimate of the model uncertainty is scale-free and dimensionless. Hence, it will be further on used for visualisation purposes.

\subsection{Transformation of predictors}

To account for multicollinearity, we used a factor analysis prior to regression analysis to produce composite indices or standardised Principal Components (PCs). These are uncorrelated and standardised transforms, and can be then used instead of the original predictors in the regression analysis (Neter et al., 1996, p. 410). Gobin (2000), for example, showed that use of standardized principal components instead of the original predictors improves the prediction for soil-landscape modelling. In addition, a stepwise regression is used as an automatic procedure to derive the 'best' subset of predictors and economize computational effort. Finally, a categorical map (soil 
map) was incorporated in the regression analysis by using indicator variables. Here, each class $(c)$ in the categorical map resulted in an additional indicator variable:

$q_{c}(s)= \begin{cases}1 & \text { if } q_{c}(s)=\operatorname{class}(c) \\ 0 & \text { otherwise }\end{cases}$

\subsection{Evaluation}

The performance of interpolation methods can be evaluated using interpolation and validation sets. The interpolation set is used to derive the sum of squares of residuals (SSE) and adjusted coefficient of multiple determination $\left(R_{a}^{2}\right)$, which describe the goodness of fit:

$$
\begin{aligned}
R_{a}^{2} & =1-\left(\frac{n-1}{n-p}\right) \cdot \frac{\mathrm{SSE}}{\mathrm{SSTO}} \\
& =1-\left(\frac{n-1}{n-p}\right) \cdot\left(1-R^{2}\right)
\end{aligned}
$$

where SSTO is the total sum of squares Neter et al. (1996), $R^{2}$ indicates amount of variance explained by model, whereas $R_{a}^{2}$ adjusts for the number of variables $(p)$ used. In many cases, a $R_{a}^{2} \geq 0.85$ is already a very stratificatory solution and higher values will typically only mean over-fitting of the data (Park and Vlek, 2002). Note that this number corresponds to the relative prediction error (Eq. (16)) of $\leq 40 \%$.

The true prediction accuracy can be evaluated by comparing estimated values $\left(\hat{z}\left(s_{j}\right)\right)$ with actual observations at validation points $\left(z^{*}\left(s_{j}\right)\right)$ in order to assess systematic error, calculated as mean prediction error (MPE):

$\mathrm{MPE}=\frac{1}{l} \cdot \sum_{j=1}^{l}\left[\hat{z}\left(s_{j}\right)-z^{*}\left(s_{j}\right)\right]$

and accuracy of prediction, calculated as root mean square prediction error (RMSPE):

$$
\operatorname{RMSPE}=\sqrt{\frac{1}{l} \cdot \sum_{j=1}^{l}\left[\hat{z}\left(s_{j}\right)-z^{*}\left(s_{j}\right)\right]^{2}}
$$

where $l$ is the number of validation points. In order to compare accuracy of prediction between variables of different type, the RMSPE can be normalized by the total variation, as in Eq. (16):

$\operatorname{RMSPE}_{r}=\frac{\mathrm{RMSPE}}{s_{z}}$

As a rule of thumb, we can consider that a value of $\mathrm{RMSPE}_{\mathrm{r}}$ close to $40 \%$ means a fairly satisfactory accuracy of prediction. Otherwise, if the values get $>71 \%$, this means that the model accounted for less than $50 \%$ of variability at the validation points and the prediction is unsatisfactory.

\subsection{Visualisation}

A typical result of (geo)statistical interpolation is a map of predictions and prediction error, which is an estimate of prediction uncertainty. These two are commonly not visualised simultaneously. This can be achieved by using the pseudo colour scale and image calculations on colours, following the Hue-SaturationIntensity (HSI) colour model (Hengl et al., 2002). We suggest the following procedure. First the prediction values need to be transformed to the hue angle by:

$\varphi_{1}=-90+z_{r} \cdot 300$

$\varphi_{2}=\left\{\begin{array}{ll}\varphi_{1}+360 & \text { if } \varphi_{1} \leq-360 \\ \varphi_{1} & \text { if } \varphi_{1}>-360\end{array}\right\}$

where $\varphi$ is the hue angle in degrees measured clockwise and $z_{r}$ are the predictions $\left(z_{r} \in[0,1]\right)$. The predictions and uncertainty (relative error) are then coded to HSI image by:

$$
\begin{aligned}
& H=\left(\varphi_{2}+360\right) \cdot \frac{240}{360} \\
& S=\left(1-u_{r}\right) \cdot 240 \\
& I=\left(1+u_{r}\right) \cdot 120
\end{aligned}
$$

where $\varphi$ is the hue angle in degrees measured clockwise, $z_{r}$ are the predictions and $u_{\mathrm{r}}$ is the prediction uncertainty $\left(u_{r} \in[0,1]\right)$. Note that these values have to be stretched before coding by using:

$z_{r}=\frac{\hat{z}-z_{1}}{z_{2}-z_{1}}$ 


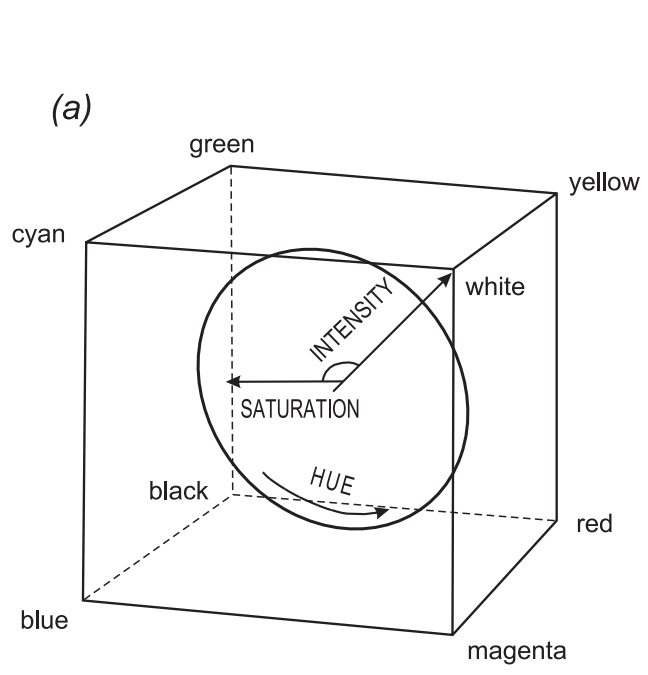

(b)

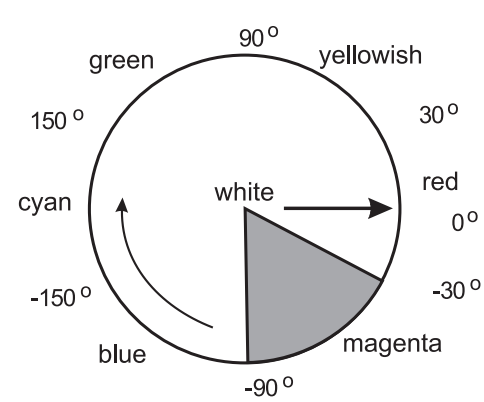

(c)

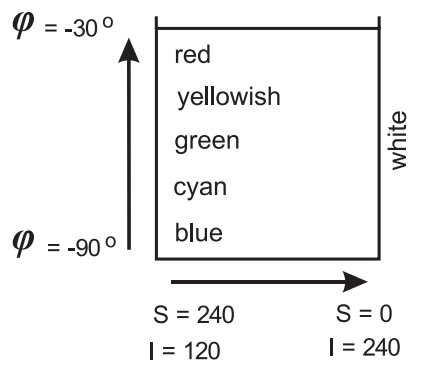

Fig. 2. Hue-Saturation-Intensity colour model in Red-Green-Blue colour cube (a), main hue types used for the visualisation (b) and the same shown using a two-dimensional legend (c). $\varphi$ is the hue angle in degrees measured counter-clockwise. See text for explanation.
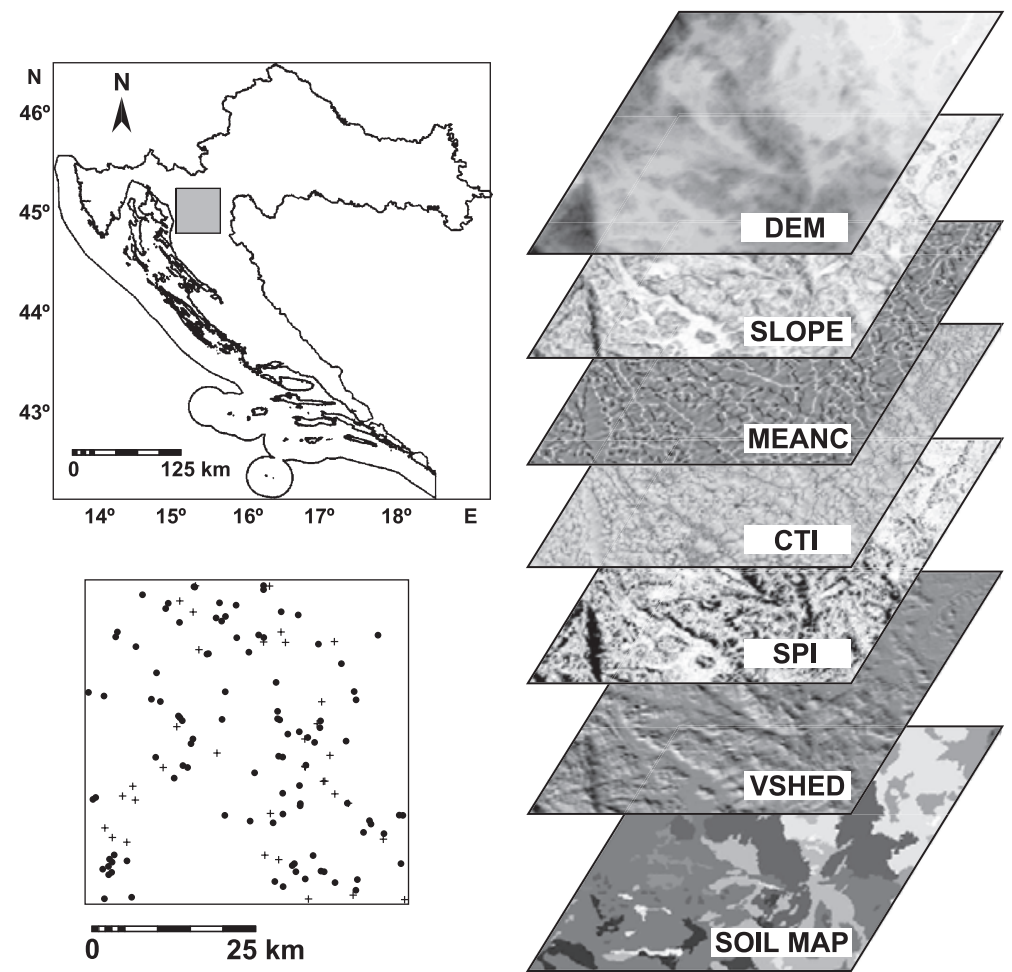

Fig. 3. Location of the study area (upper-left), profiles used for interpolation $(\bullet)$ and validation (+) (lower-left) and maps of predictors (right). 
$u_{r}=\frac{\sigma_{\mathrm{E}, r}-u_{1}}{u_{2}-u_{1}}$

where $\hat{z}$ is the prediction map derived using Eq. (13) and back-transformed using Eq. (14), $\sigma_{\mathrm{E}, r}$ is the relative prediction error map derived using Eq. (9) and standardised using Eq. (16), $z_{1}$ and $z_{2}$, and $u_{1}$ and $u_{2}$ are the lower and upper inspection range limits for the predicted values and relative prediction error. From the HSI images, the RGB composite image can be derived in ILWIS using (Unit Geo Software Development, 2001):

$z_{\mathrm{RGB}}=\operatorname{colorhsi}(\mathrm{H}, \mathrm{S}, \mathrm{I})$

Note that, from Eqs. (23)-(27), the lower values are coded bluish (hue angle from $-90^{\circ}$ to $-150^{\circ}$ and highest values are coded reddish (hue angle from $-330^{\circ}$ to $-30^{\circ}$. Consequently, the intermediate values are coded with cyan, green and yellowish (Fig. 2b). This model corresponds to the pseudo-colour scale used in many GIS packages for visualising continuous variables. Also note that a part of the hue circle representing magenta $\left(-30^{\circ}\right.$ to $\left.-90^{\circ}\right)$ is omitted to avoid confusion between high and low values. The second property of the HSI-coded image is that uncertainty is coded with whiteness. This has often proven to be the most suitable colour variable for visualisation of uncertainty (Jiang et al., 1995). In this case, fully saturated colour indicates lowest uncertainty and white colour indicates full uncertainty within the given thresholds.

In addition to the colour map, we developed a special two-dimensional legend (see Figs. 2c and 8e) to accompany the HSI-coded image. The vertical direction indicates change of prediction values (from $-90^{\circ}$ to $-30^{\circ}$ ), while the horizontal direction indicates uncertainty and is coded with a linear increase of both intensity and saturation, i.e. whiteness. This visualisation algorithm can be applied in any image processing or general GIS package, which allows calculations on colours.

\subsection{Case study}

A set of 135 profile observations from the Croatian national Soil Geographical Database (Martinović and Vranković, 1997) was used as a case study. It was randomly divided into a interpolation (100 points) and validation set (35 points). The study

Table 1

Descriptive statistics for target variables, predictors and their transforms: MEAN-mean, STDEV-standard deviation, MED-median, MINminimum, MAX-maximum, SKEW-skewness, KURT-kurtosis

\begin{tabular}{|c|c|c|c|c|c|c|c|c|c|}
\hline & \multicolumn{5}{|c|}{ Target variables } & \multicolumn{4}{|l|}{ Predictors } \\
\hline & OM \% & $\mathrm{PH}$ & DEPTH $(\mathrm{cm})$ & $\mathrm{DEM}(\mathrm{m})$ & SLOPE \% & $\operatorname{MEANC}\left(\mathrm{m}^{-1}\right)$ & CTI & SPI & VSHED \\
\hline MEAN & 9.7 & 6.25 & 19.8 & 634 & 15.1 & -1.19 & 9.1 & 90.3 & 0.63 \\
\hline STD & 6.8 & 0.88 & 9.6 & 267 & 12.9 & 6.86 & 2.5 & 97.8 & 12.17 \\
\hline MED & 7.3 & 6.20 & 18.5 & 604 & 12.3 & 0.23 & 8.5 & 56.8 & 1.00 \\
\hline MIN & 2.1 & 4.50 & 4.0 & 207 & 0.9 & -27.47 & 5.4 & 0.0 & -30.60 \\
\hline MAX & 33.4 & 7.70 & 45.0 & 1298 & 51.1 & 14.14 & 17.7 & 482.8 & 33.00 \\
\hline SKEW & 1.51 & -0.18 & 0.57 & 0.41 & 0.85 & -1.12 & 1.14 & 1.60 & 0.01 \\
\hline KURT & 2.00 & -0.99 & -0.01 & -0.53 & -0.23 & 1.97 & 1.01 & 2.71 & 0.98 \\
\hline \multicolumn{10}{|c|}{ Transforms } \\
\hline & SPC1 & SPC2 & SPC3 & SPC4 & SPC5 & SPC6 & & & \\
\hline MEAN & 103 & -48 & 86 & 79 & 184 & 56 & & & \\
\hline STD & 105 & 55 & 55 & 53 & 31 & 28 & & & \\
\hline MED & 104 & 38 & 95 & 74 & -185 & 48 & & & \\
\hline MIN & -84 & -192 & -61 & -47 & -244 & -36 & & & \\
\hline MAX & 362 & 54 & 207 & 217 & -96 & 138 & & & \\
\hline SKEW & 0.12 & -0.55 & -0.56 & 0.04 & 0.21 & 0.10 & & & \\
\hline KURT & -0.99 & -0.32 & 0.16 & 0.28 & -0.28 & 0.78 & & & \\
\hline
\end{tabular}


(a)

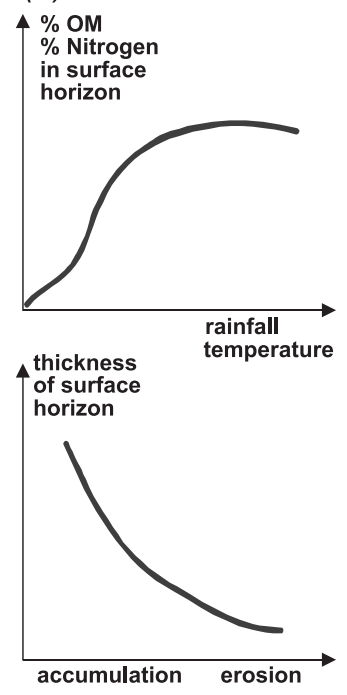

(b)
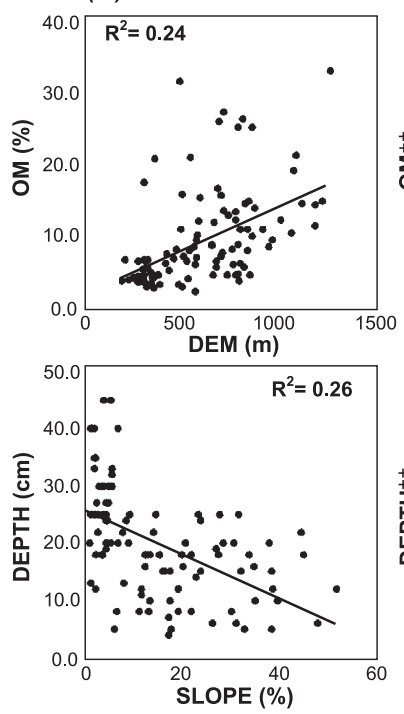

(c)
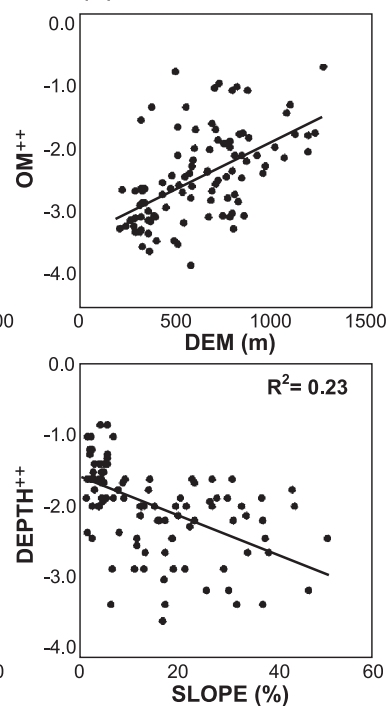

(d)
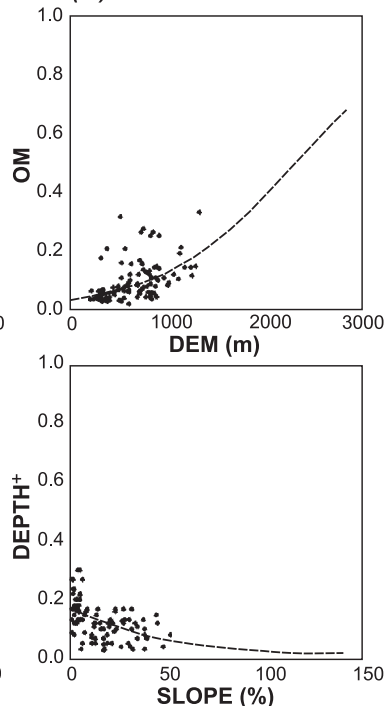

Fig. 4. Comparison of empirical relationships (a), observed relationship (b), observed after the logit transformation (c) and back transformed models (d).

area is a $50 \times 50 \mathrm{~km}$ square located in the central part of Croatia. As target variables, the organic matter in the topsoil (OM), measured using a colorimetric wet oxidation method and expressed in \%, the topsoil $\mathrm{pH}$ measured in $\mathrm{H}_{2} \mathrm{O}(\mathrm{PH})$ and thickness of topsoil horizon expressed in $\mathrm{cm}$ (DEPTH) were used.

As predictors (auxiliary maps), we used five relief parameters derived from the $100 \times 100 \mathrm{~m}$ resolution elevation data: elevation (DEM), slope (SLOPE), mean curvature (MEANC), Compound Topographic Index (CTI), Stream Power Index (SPI) and viewshed (VSHED) (Fig. 3), all derived in ILWIS (Hengl et al., 2003a). These were first linearly stretched in an image processing software to a range of $0-255$ to give each map equal contrast and then transformed to standardised principal components (further referred to as the Soil Predictive Components SPCs) using factor analysis in ILWIS. The 1:300.000 K soil map of Croatia was used as the categorical layer (Bogunović et al., 1998). There were 28 soil mapping units (further referred to as SMU) in the study area. Due to a low number of points in the interpolation set, we first reduced the number of units to nine by merging some taxonomically adjacent units. Finally, there were six SPCs and nine SMUs making 15 predictors in total.

\subsection{Data analysis}

The OM, DEPTH and PH were first transformed using Eq. (11):

$$
\begin{aligned}
& \mathrm{OM}^{++}=\ln \left(\frac{\mathrm{OM}^{+}}{1-\mathrm{OM}^{+}}\right) \\
& \mathrm{PH}^{++}=\ln \left(\frac{\mathrm{PH}^{+}}{1-\mathrm{PH}^{+}}\right) \\
& \mathrm{DEPTH}^{++}=\ln \left(\frac{\mathrm{DEPTH}^{+}}{1-\mathrm{DEPTH}^{+}}\right)
\end{aligned}
$$

where the $\mathrm{OM}^{+}, \mathrm{PH}^{+}$and $\mathrm{DEPTH}{ }^{+}$are values standardised to $0-1$ scale:

$$
\begin{gathered}
\mathrm{OM}^{+}=\frac{\mathrm{OM}-0}{100-0} \\
\mathrm{PH}^{+}=\frac{\mathrm{PH}-4.1}{8.8-4.1}
\end{gathered}
$$


$\mathrm{DEPTH}^{+}=\frac{\mathrm{DEPTH}-0}{150-0}$

In the case of OM and DEPTH we used the minimum and maximum values measured in the whole of Croatia. Also note that zero measurements need to be replaced with an arbitrary small number, e.g. the precision of measuring a variable in the laboratory or in the field.
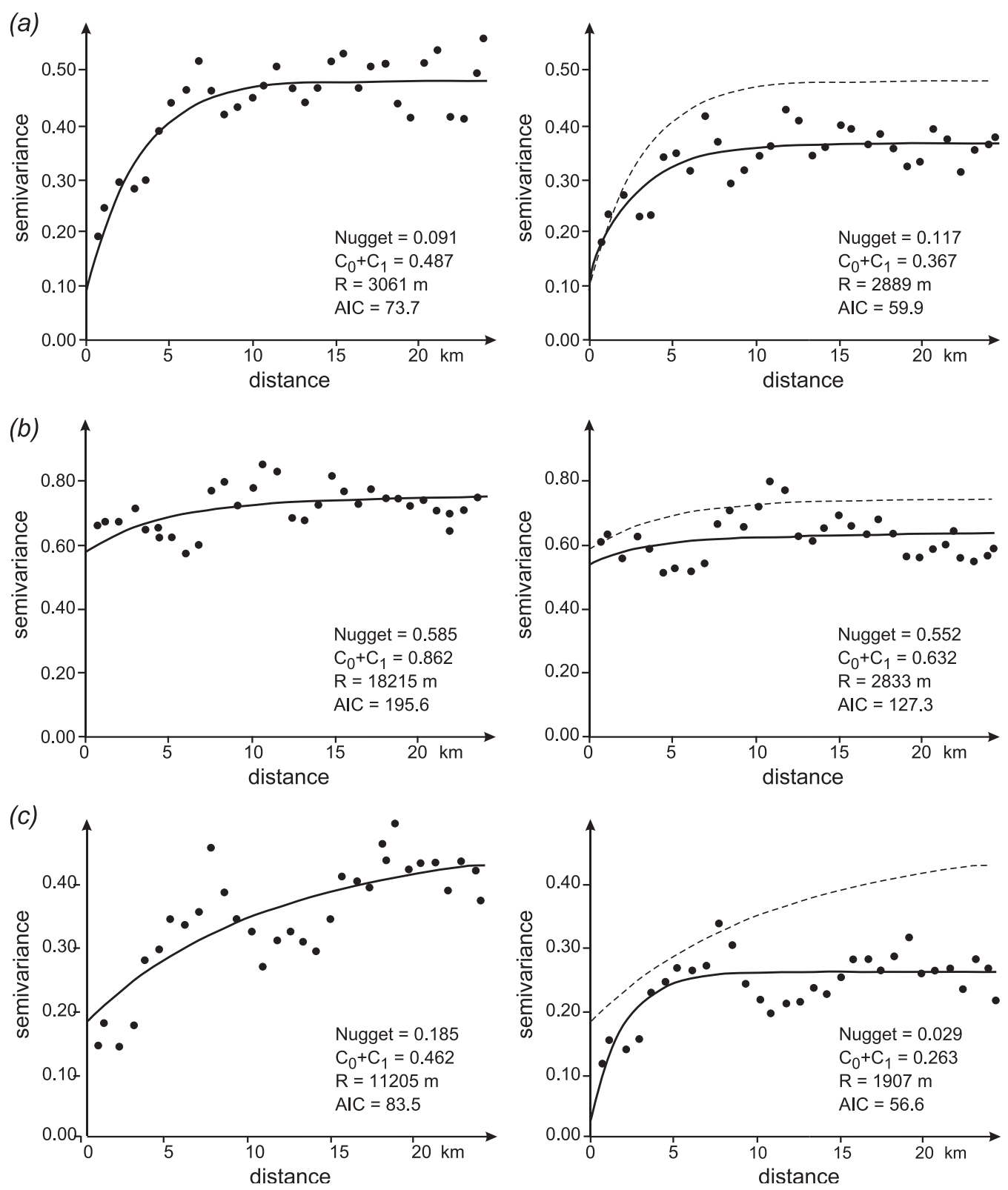

Fig. 5. Semivariograms of target variables (left graphs and dotted line) and their residuals (right graphs): $\mathrm{OM}^{++}(\mathrm{a}), \mathrm{PH}^{++}(\mathrm{b})$ and DEPTH ${ }^{++}(\mathrm{c})$. All fitted in VESPER using an exponential model. 
First, prediction maps of OM, PH and DEPTH were made from the soil map by averaging profiles per SMU (Burrough, 1993). Second, the variables were interpolated using ordinary kriging $(\mathrm{OK})$ and OLS multiple regression (MR). These three prediction methods were then compared with the RK within the generic framework.

The spatial dependence structure of soil variables and residuals was modelled in VESPER using automated variogram fitting (Minasny et al., 2002). We used an exponential model and a limiting distance of $25 \mathrm{~km}$ in all cases. In addition, the variogram modelling in VESPER gave the Akaike Information Criterion (AIC), which was used to compare different models for the goodness of fit (McBratney and Webster, 1986). The GLS coefficients were used to derive the drift maps using the map calculation in ILWIS. The re-estimated residuals were then interpolated and added to the fitted drift. The final estimates were then back-transformed to their original scale using the Eq. (14). Matrix calculations and fitting of the target variables using the stepwise regression was done in the S-PLUS statistical package (MathSoft, 1999). Although most of the processing steps are feasible with a standard PC, the calculation of the variance of the prediction error (Eq. (9)) can be time-consuming, even for smaller size data sets.

\section{Results}

\subsection{Regression modelling}

Inspection of the distributions of target variables at primary locations showed that both OM and DEPTH have positively skewed distributions (Table 1). Also the predictors, especially SPI, CTI and MEANC show distinct asymmetry in their distributions. Similarly, the first univariate linear regression models showed that the residuals are skewed around the regression line and therefore do not satisfy the normality requirement for both regression analysis and kriging (Fig. 4b). In this case, the correlation test of normality for residuals (Neter et al., 1996, p. 111) gave coefficient of correlation of $0.912(\mathrm{OM})$ and 0.983 (DEPTH) between ordered residuals. Note that the critical value of coefficient of correlation between ordered residuals for $n=100$ and 0.05 level of significance is 0.987 (Looney and Gulledge, 1985), which means that both variables significantly depart from the normal distribution. After the logit transformation of the target variables $\left(\mathrm{OM}^{++}, \mathrm{PH}^{++}\right.$, DEPTH $\left.{ }^{++}\right)$, the models became symmetrical around the fitted linear models, and the coefficients of correlation between ordered residuals were higher for $\mathrm{OM}^{++}(0.982)$ and similar for $\mathrm{DEPTH}^{++}(0.981)$. This was also reflected in an increased $R^{2}$ (Fig. 4c). Note that for DEPTH under simple linear modelling, the predictions in areas of high slope (SLOPE $>60 \%$ ) would yield negative estimates. The residuals for $\mathrm{DEPTH}^{++}$, however, show skewness even after the transformation. In this case, this was a reflection of the log-normal distribution of SLOPE. Note that the observed relationships (Fig. 4d) correspond to the hypothetical plots described by Buol and Hole (1980) (Fig. 4a). This phenomenological correspondence is an extra guarantee to apply these models in spatial prediction.

The results of the factor analysis showed that there is an overlap in information and that the data can be reduced. The first four SPCs accounted for more than $90 \%$ of the total variation in the bands $(42.6 \%, 21.3 \%$, $14.5 \%$ and $12.0 \%$ ). SPC1 as the main component was explained by variation in SLOPE, SPI, CTI and DEM. SPC2 accounted mainly for the variation in MEANC and SPI, while the third and fourth component accounted for DEM and VSHED. The fifth and sixth

Table 2

Summary results of the step-wise regression analysis for $\mathrm{OM}^{++}$, $\mathrm{PH}^{++}$and $\mathrm{DEPTH}^{++}$and improved coefficient estimates $(\mathrm{n}=100)$

\begin{tabular}{llcl}
\hline $\begin{array}{l}\text { Target } \\
\text { variable }\end{array}$ & $\begin{array}{l}\text { Selected } \\
\text { Predictors }\end{array}$ & $\begin{array}{l}\text { Regression } \\
\text { coefficients(OLS*) }\end{array}$ & $\begin{array}{l}\text { Regression } \\
\text { coefficients(GLS**) }\end{array}$ \\
\hline $\mathrm{OM}^{++}$ & intercept & -3.124 & -3.161 \\
& SPC1 & 0.003228 & 0.003143 \\
& SPC4 & 0.004843 & 0.005468 \\
& SMU8 & -0.7712 & -0.4844 \\
$\mathrm{PH}^{++}$ & intercept & -0.4258 & -0.4194 \\
& SMU5 & 0.6598 & 0.7010 \\
& SMU6 & 0.9183 & 0.7008 \\
$\mathrm{DEPTH}^{++}$ & intercept & -1.667 & -1.664 \\
& SPC1 & -0.003212 & -0.003131 \\
& SPC3 & 0.002264 & 0.002189 \\
& SPC4 & -0.002726 & -0.002823 \\
\hline
\end{tabular}

* OLS-Ordinary least square estimation.

** GLS - General least square estimation based on the spatial covariance matrix of residuals. 
components showed some features already seen in the first four components and probably represent noise and artefacts in the relief parameters. Note that the SPCs show much lower skewness and kurtosis than the original predictors (Table 1).

The step-wise regression substantially reduced the number of predictors. In the case of $\mathrm{OM}^{++}$, it selected SPC1, SPC4 and SMU8 as the optimal sub-set for prediction, while in the case of $\mathrm{DEPTH}^{++}$, the algorithm selected SPC1, SPC3 and SPC4. In both cases

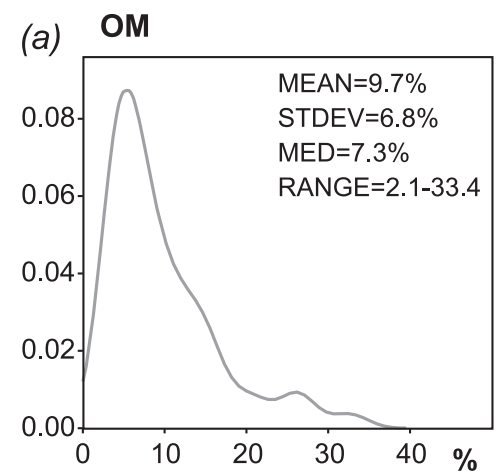

(b)
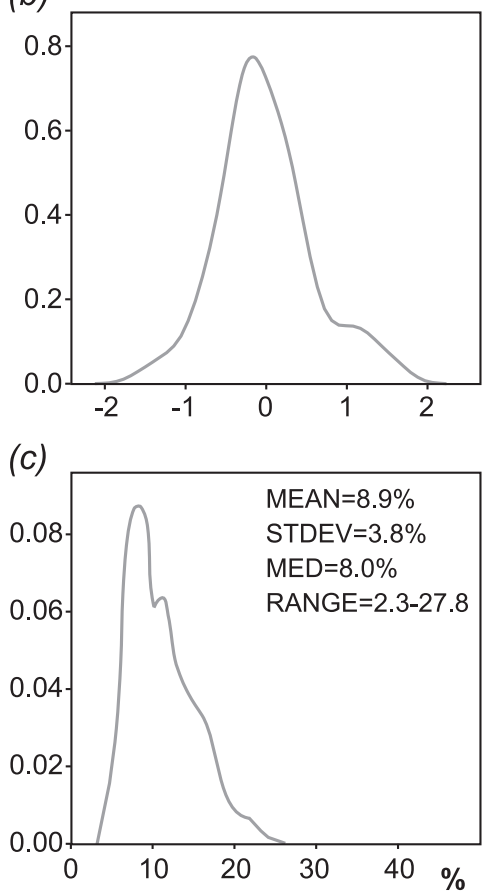

the correlation was significant $\left(R_{a}^{2}=0.33\right.$ for $\mathrm{OM}^{++}$ and $R_{a}^{2}=0.40$ for $\mathrm{DEPTH}^{++}$). In the case of $\mathrm{PH}^{++}$, the coefficient of multiple determination was small $\left(R_{a}^{2}=\right.$ 0.14 ), but still significant at the 0.05 level, indicating weak correlation with the predictors. Here, the only significant predictors were SMU5 and SMU6. The normality test for residuals showed that in all cases the residuals did not depart significantly from a normal distribution with coefficient of correlation between ordered residuals of 0.986 for $\mathrm{OM}^{++}, 0.981$ for $\mathrm{PH}^{++}$
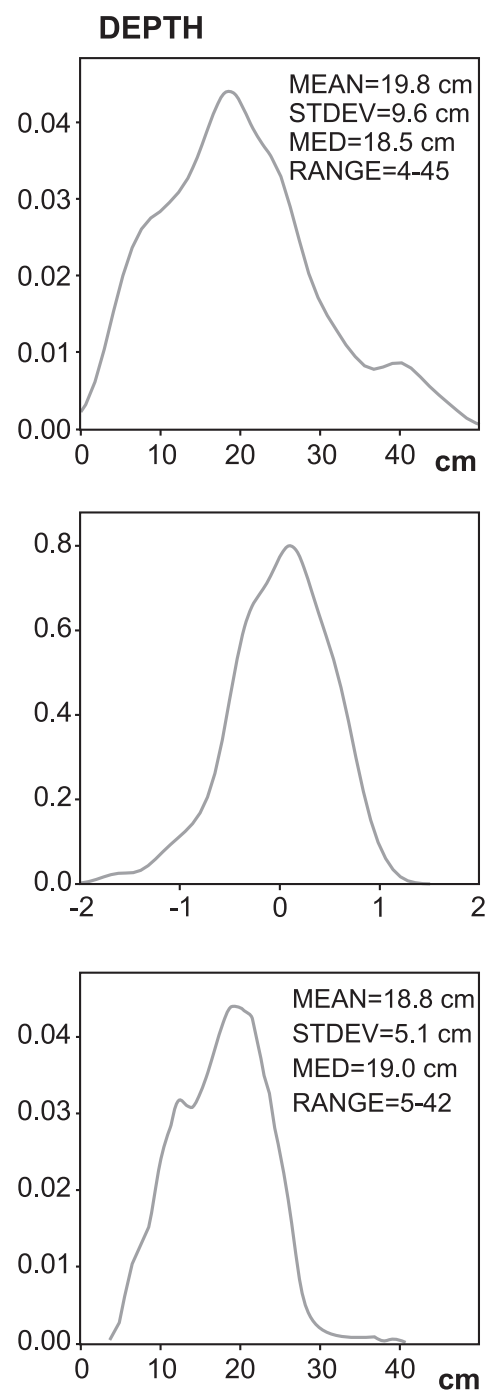

Fig. 6. Density histograms and summary statistics for: target variables (OM and DEPTH) at primary locations (a), GLS residuals (b) and prediction maps (c). MEAN—mean, STDEV—standard deviation, MED—median and RANGE—range. 
and 0.989 for $\mathrm{DEPTH}^{++}$(see also density histograms in Fig. 6b).

\subsection{Geostatistical analysis}

Both $\mathrm{OM}^{++}$and DEPTH ${ }^{++}$showed a clear spatial dependence, whereas the variogram of $\mathrm{PH}^{++}$was dominated by a pure nugget effect (Fig. 5a). For $\mathrm{OM}^{++}$automated variogram modelling gave a small nugget and shorter range parameter (3 km) (Fig. 5b), whereas for $\mathrm{DEPTH}^{++}$, the range parameter was fairly large $(11.2 \mathrm{~km})$. Analysis of spatial correlation of residuals reflected the success of regression fitting: the range of spatial dependence was much shorter and the sill was proportionally smaller to the variation accounted by regression modelling. Moreover, variograms of residuals tend to show a shorter range and bounded sill, which indicates that the drift has indeed been removed. This is especially distinct for $\mathrm{DEPTH}^{++}$ where the target variable showed almost an unbounded variogram, whereas the residuals showed an almost five times shorter range of spatial dependence and $43 \%$ smaller sill (Fig. 5c). The AIC confirms that the variograms of residuals are somewhat easier to fit. Here, the best fit, i.e. the smallest AIC, was obtained for the residuals of $\mathrm{DEPTH}^{++}$.

Regression coefficients using OLS and GLS estimation are given in Table 2. The differences between coefficients were in all cases relatively small, which indicates that there is no significant spatial clustering between the points.

\subsection{Bias and accuracy of prediction}

A problem with the logit transformation is that the back-transformation gives only an unbiased estimate of the median, as for example in the case of log-normal kriging. This is usually reflected in somewhat lower predictions, especially if values are grouped around zero. In this case, the mean of the interpolation set $\left(z\left(s_{i}\right)\right)$ was somewhat higher than the mean of fitted values $\left(\hat{z}\left(\mathrm{~s}_{\mathrm{i}}\right)\right): 9.7 \%$ as compared to $9.1 \%$ for $\mathrm{OM}$ (or $6.7 \%$ lower in relative measures) and $19.8 \mathrm{~cm}$ compared to $19.5 \mathrm{~cm}$ for DEPTH (or $1.5 \%$ lower). Comparison of histograms of the prediction maps for the same properties, also gave somewhat lower means of $8.9 \%$ for OM (or $8.2 \%$ lower in relative measures) and $18.8 \mathrm{~cm}$ for DEPTH (or 5.1\% lower) (Fig. 6c). The medians in the prediction maps, however, are somewhat higher than the medians at primary locations: $8.0 \%$ compared to $7.3 \%$ for $\mathrm{OM}$ and $19.0 \mathrm{~cm}$ compared to $18.5 \mathrm{~cm}$ (Fig. 6c). It seems, therefore, that there is no need for an unbiased back-transformation as the histograms, before and after the back-transformation, in general match. Note that the ranges in the prediction

Table 3

Comparison of interpolation methods for goodness of fit $\left(\mathrm{R}_{\mathrm{a}}^{2}\right)$, bias (MPE) and accuracy of the prediction at validation points (RMSPE)

\begin{tabular}{|c|c|c|c|c|c|c|}
\hline & \multicolumn{3}{|c|}{ Interpolation set } & \multicolumn{3}{|c|}{ Validation set } \\
\hline & Method* & SSE* & $\mathrm{R}_{\mathrm{a}}^{2}$ & MPE & RMSPE & RMSPE$_{\mathrm{r}}^{*}(\%)$ \\
\hline \multirow[t]{4}{*}{ OM (\%) } & SOIL & - & - & -1.28 & 5.3 & 68.2 \\
\hline & $\mathrm{OK}$ & 3.2 & - & 0.01 & 5.2 & 66.5 \\
\hline & MR & 34.7 & 0.31 & -0.10 & 3.4 & 44.1 \\
\hline & RK & 5.3 & - & -0.04 & 4.2 & 53.3 \\
\hline \multirow[t]{4}{*}{ PH (-) } & SOIL & - & - & 0.11 & 1.024 & 128.1 \\
\hline & OK & 49.7 & - & 0.00 & 0.932 & 116.6 \\
\hline & MR & 64.5 & 0.13 & 0.06 & 0.892 & 111.5 \\
\hline & RK & 50.4 & - & 0.01 & 0.885 & 110.7 \\
\hline \multirow[t]{4}{*}{ DEPTH (cm) } & SOIL & - & - & 1.41 & 9.1 & 88.7 \\
\hline & $\mathrm{OK}$ & 10.4 & - & 0.69 & 8.5 & 83.3 \\
\hline & MR & 23.4 & 0.40 & 1.69 & 8.8 & 85.4 \\
\hline & RK & 0.7 & - & 0.15 & 6.8 & 66.5 \\
\hline
\end{tabular}

SOIL — prediction from the soil map only; OK-ordinary kriging; MR - multiple regression; RK-regression kriging.

Values for transformed variables $\left(\mathrm{OM}^{++}, \mathrm{PH}^{++}\right.$and $\left.\mathrm{DEPTH}^{++}\right)$.

$\mathrm{RMSPE}_{\mathrm{r}}$-relative prediction error (\%). 
maps are somewhat narrower due to the smoothing effect of RK.

The summary comparison of prediction methods at the validation points is presented in Table 3. Note that the GLS coefficients result in somewhat higher SSE. For example, in the case of $\mathrm{OM}^{++}$, the SSTO is 51.4; after the regression analysis the SSE has decreased to 34.7 , meaning that $33 \%$ of the variation has been explained by the model. The GLS estimation, however, resulted in a somewhat higher SSE (36.7). Finally, the SSE after kriging the residuals has decreased to 5.3, indicating that the RK model accounted for almost $90 \%$ of the total variation at the primary location grids $(100 \times 100 \mathrm{~m})$. In the case of OM, RK achieved slightly better relative prediction accuracy than OK (53.3\% versus $66.5 \%)$. In both cases the bias was small. Similarly, RK achieved a higher accuracy of prediction $(66.5 \%$ versus $83.3 \%)$ and a smaller bias $(0.15$ versus 0.69 $\mathrm{cm}$ ) for predicting DEPTH, when compared with OK. In general, the soil map was shown to be an inefficient predictor in all cases except for prediction of $\mathrm{OM}$ in topsoil. Relatively low bias for RK in all cases indicates that the logit transformation and use of SPCs served their purpose. The prediction of PH has proven to be difficult with a relative prediction error greater than $100 \%$. This means that all compared methods can show almost any value within the given range and there is no justification for production of a $\mathrm{PH}$ map.

Comparison of different prediction methods for mapping DEPTH is shown in Fig. 7. The soil map in general over-smoothed the values, except for two SMUs (Fig. 7b). On the contrary, OK map (Fig. 7c) shows rather gradual transitions with fairly low level of detail, whereas the RK map (Fig. 7d) reflects change in elevation, slope and exposition. Finally the RK map (Fig. 7e) yields more detail than the OK map, at the same time showing the hot-spots not visible in the MR map.

Visualisation of the predicted DEPTH map together with the prediction error is given in Fig. 8. The composite variance of RK reflects both the arrangement of points in geographical space (the kriging variance of residuals) and areas of extrapolation in attribute space. Note that the areas of higher slopes have been under-sampled (diagonal strips), which is also reflected in the prediction error map (Fig. 8b).
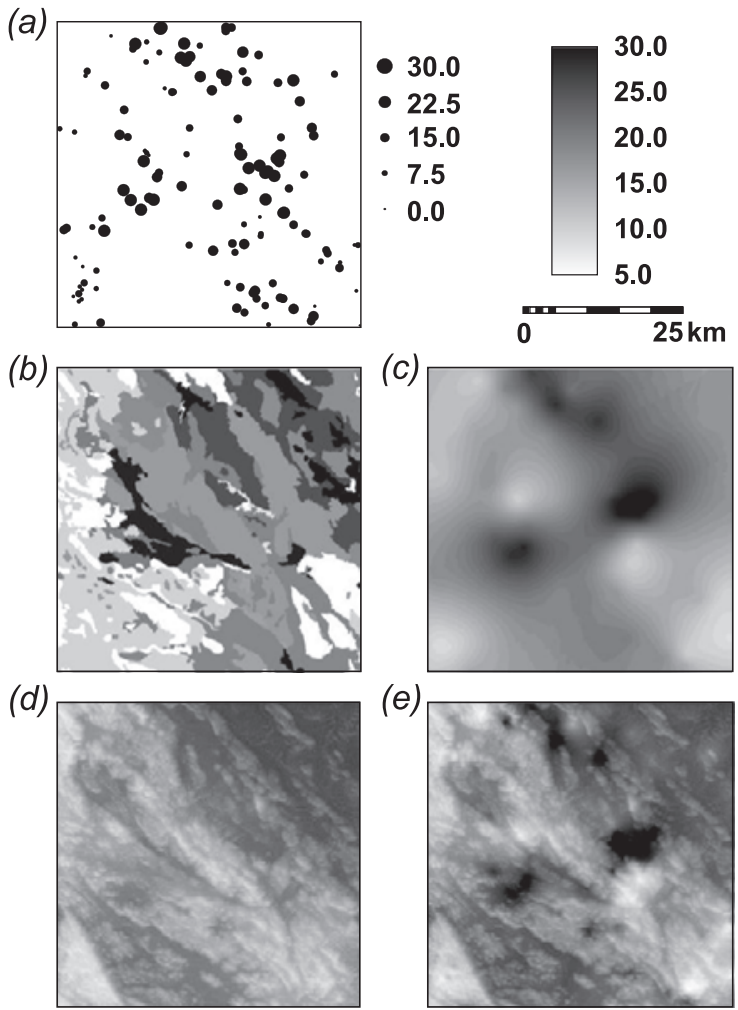

Fig. 7. Topsoil thickness (DEPTH) measured at 135 locations (a) comparison of predictions made by using: soil map only (b), ordinary kriging (c), plain regression (d) and regression-kriging (e). Note that the hot spots re-appear in the RK prediction map.

This corresponds to previous results by Papritz and Stein (1999, p. 112), for example.

The combined visualization gives insight into the relationship between uncertainty and input data for the given thresholds. In this case, we visualised prediction of DEPTH using the following thresholds: $z_{1}=5$ and $z_{2}=30 \mathrm{~cm}$ for the predictions and $u_{1}=0.10$ and $u_{2}=0.20$ and 0.25 for the errors (Fig. 8). The corrected brightness values are then: (a) equal to the original RGB for a relative uncertainty equal or less than 0.10 , and (b) completely white for relative uncertainty equal or higher than 0.20 or 0.25 . In the first case (Fig. 8c), the visualisation resulted in most of the map distant from the points being pale, while in the case of a maximum feasible threshold (0.25), the HSI-coded image shows that prediction was efficient in most of the study area 
(a)
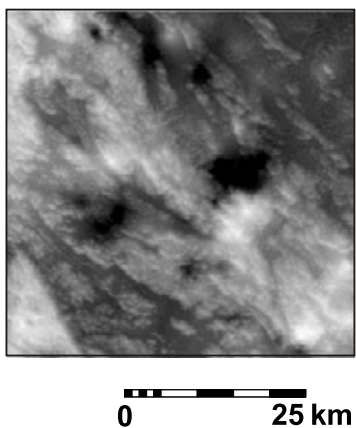

(c)

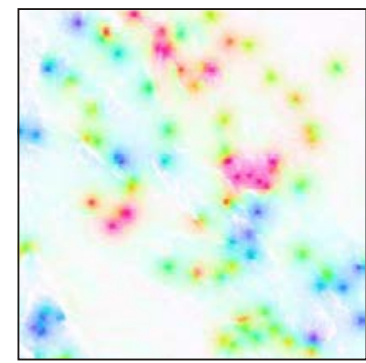

(d)

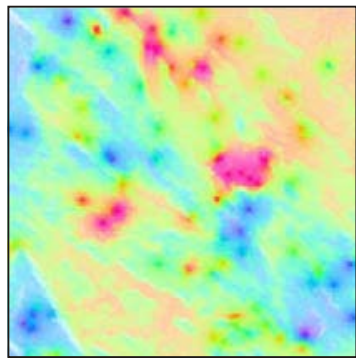

cm

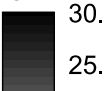

25.0

20.0

15.0

10.0

5.0
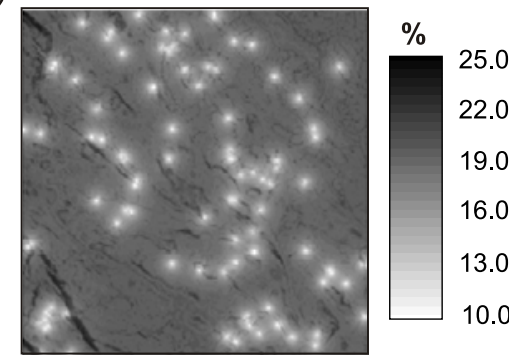

(e)

$\mathrm{u} 1=\mathbf{0 . 4 0}$

$\mathrm{u}_{2}=\mathbf{0 . 8 0}$

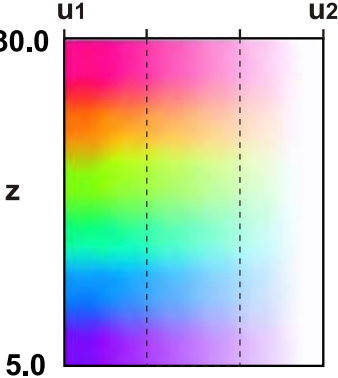

(b)

5.0

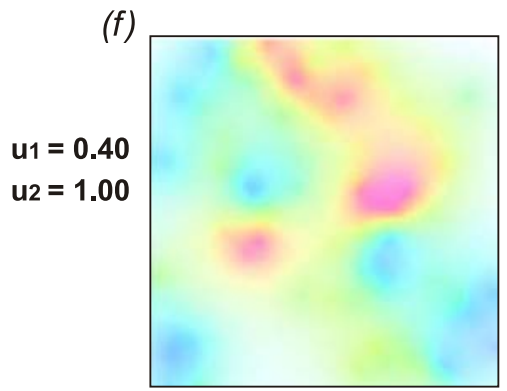

Fig. 8. Generic visualization of the RK prediction map for DEPTH in $\mathrm{cm}$ (a) and relative error (b), the HSI colour images with two inspection ranges (c and d), two dimensional legend (e) and referent OK prediction map visualised using the same tresholds (f).

(Fig. 8d). A visual comparison between the HSIcoded RK and OK (Fig. 8f) maps shows that the OK predictions are somewhat less certain and, consequently, the colours are less distinct. See the supplementary materials for full-colour animation of prediction uncertainty (http://www.pfos.hr/ hengl/ GRK/).

\section{Conclusions and discussion}

In this study we integrated several methodological steps to provide a framework for generic spatial prediction and visualisation of soil data. The key principle was to employ most of the available regression and kriging methods and let the system exploit 'the best' of the data. The results show that the proposed methodology improves prediction efficiency, while ensuring a relative normality of residuals and predictors. Especially the logit transformation proved to be a useful step to model non-linear relationships and force prediction values to be within the physical limits. It is also attractive for a general case because it can be used to model both linear and curvilinear relationships with one or two inflection points and both quantitative and categorical target variables. The factor analysis on map sets was efficiently used to remove multicollinearity and reduce 
asymmetry in distributions. This helped the step-wise regression algorithm to come to an optimal subset of uncorrelated predictors. When the SPCs are at the same scale, then also the regression coefficients can be directly compared. Finally, visualisation of both predictions and prediction uncertainty offers a possibility to enhance visual exploration of the data uncertainty and make comparisons between different prediction methods. In several aspects of the developed framework, we advocate use of flexible statistical methods, such as factor analysis, step-wise selection of an optimal subset of predictors, logit transformation and automated variogram fitting. These flexible methods open a possibility to develop a user-friendly bundle algorithm that can be implemented in a GIS. Eventually, a user will be able to select a point map and maps of predictors, define some minimum needed criteria and then run the spatial prediction at once.

Recently, sources of auxiliary data are increasingly available from digital terrain modelling parameters to various air-and space-born remote sensing images. There is much auxiliary information at hand nowadays, even at farm level, i.e. for precision agriculture (McBratney et al., 2003). The auxiliary variables in this study were cheaply obtained by digital terrain analysis, which makes the method inexpensive. Hence, the plain geostatistical methods are likely to be replaced with the regression-kriging techniques. One should keep in mind that both ordinary kriging and regression analysis are only special cases of one universal method of spatial prediction. In some cases, however, there will be no help from auxiliary maps and in other cases there will be no need to apply kriging (e.g. in the case of the pure nugget effect). Here, the key measures to decide on which method to use can be, for example, the correlation strength with auxiliary variables and distance at which semivariance reaches $90 \%$ of the sill (Fig. 9).

The limitations of RK are that it is more complex technique and, if misused, can give even worse estimates than straightforward ordinary kriging (Goovaerts, 1999a). Therefore, development of a fully automated generic method is still unrealistic. For example, we experienced problems with automatic fitting of the variogram functions in VESPER. Automatically fitted variogram parameters for $\mathrm{PH}$ did not

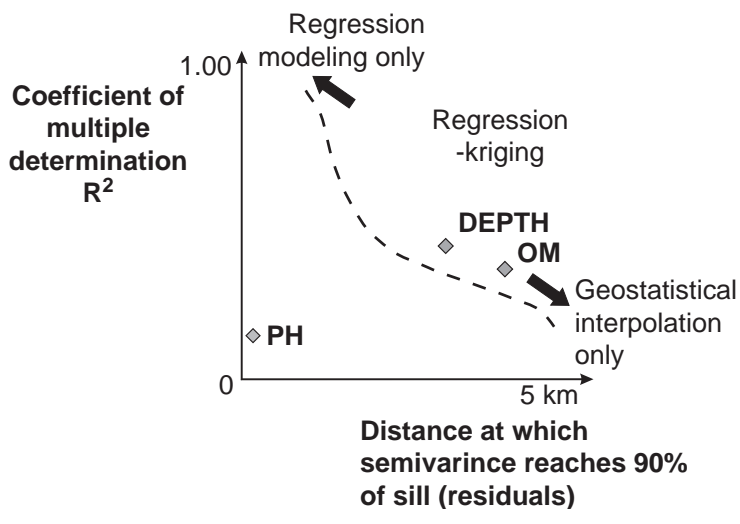

Fig. 9. Regression-krigging, plain geostatistical and regression techniques in relation to the correlation coefficient $\left(R^{2}\right)$ and distance at which semivariance reaches $90 \%$ of sill (spatial auto-correlation of residuals). Spatial prediction of $\mathrm{PH}$ was inefficient.

show any physical meaning and needed to be adjusted by hand. This asks for a set of additional remedial measures. Similarly, we cannot guarantee that the sigmoidal shape is truly generic for all cases. There will be cases with more inflection points in the correlation plots, which will be more difficult for this framework to handle. Nevertheless, logit transformation has proven to be more beneficial for prediction than a simple linear regression.

Another constraint of RK is the number of point samples required to fit the regression model. Usually a large number of samples is needed to fit some 10-20 environmental variables. As a rule, Draper and Smith (1998) suggest at least 10 complete sets of observations for each potential variable to be included, while Ott and Longnecker (2001) show that the real minimum is $2 p+20$, where $p$ is the number of predictors. In this case, due to the use of indicator variables, the size of the interpolation set was fairly close to the minimum required number ( 15 predictors to fit 100 points). It should be also emphasized that a point data set with a fairly equal spreading of points is more appropriate for regression-kriging, which is not a requirement for the plain CLORPT techniques.

In this study we have only dealt with the spatial (2D) aspect of soil variability. Note that there are three more aspects of soil variability that also play a role: temporal variability, depth (3D) and support size (Florinsky et al., 2002). Spatial prediction of PH was probably limited due to measurement errors, high 
local variation and overseen factors. From the database description, we could not conclude at which part of the season the data were collected and what was the measurement error. If measurement errors are large and if data were collected during different seasons, not even the most optimal interpolator would make usable predictions. In such cases, a larger number and better quality of soil environmental variables should be used to improve predictions. Eventually, if not even these measures are useful, more intensive sampling strategies at fixed conditions (same season, same depths, same blocks of land) are required.

The next steps will be to integrate this statistical framework into a GIS package and provide a userfriendly procedure, which can be used to interpolate existing profile datasets. The methodology can then be extended so that it includes the temporal and internal (depth) variability of soil variables as well. Finally, the following three topics seems to be especially challenging for the future research:

- Development of soil genesis simulation models rather than just data fitting techniques (Heuvelink and Webster, 2001). Some rudimentary applications already exist (Minasny and McBratney, 2001).

- Development of robust automated variogram modelling algorithms that will account for serious outliers and over-parameterisation or over-fitting of the data.

- Further integration of geostatistical modules within GIS packages. Here, a promising development is the integration of geostatistical packages such as GSTAT with open-source statistical packages such as R or GIS packages like GRASS (Pebesma, 2003).

\section{References}

Birkeland, W., 1999. Soils and Geomorphology, 3rd ed. Oxford Univ. Press, New York.

Bishop, T., McBratney, A., 2001. A comparison of prediction methods for the creation of field-extent soil property maps. Geoderma 103 (1-2), 149-160.

Bogunović, M., Vidaček, V., Husnjak, S., Sraka, M., 1998. Inventory of soils in croatia. Agriculturae Conspectus Scientificus 63 (3), 105-112.

Bourennane, H., King, D., 2003. Using multiple externals drifts to estimate a soil variable. Geoderma 114, 1-18.

Bourennane, H., King, D., Chery, P., Bruand, A., 1996. Improving the kriging of a soil variable using slope gradient as external drift. European Journal of Soil Science 47 (4), 473-483.

Bourennane, H., King, D., Couturier, A., 2000. Comparison of kriging with external drift and simple linear regression for predicting soil horizon thickness with different sample densities. Geoderma 97 (3-4), 255-271.

Buol, S., Hole, F., 1980. Soil Genesis and Classification. Iowa State University Press, Ames.

Burrough, P., 1993. Soil variability: a late 20th century view. Soils and Fertilizers 56 (May), 529-562.

Chiles, J., Delfiner, P., 1999. Geostatistics: Modeling Spatial Uncertainty. Wiley, New York.

Christensen, R., 1990. Linear Models for Multivariate, Time, and Spatial Data. Springer, New York.

Cressie, N., 1993. Statistics for Spatial Data, Revised Ed. Wiley, New York.

Deutsch, C., Journel, A., 1992. Geostatistical Software Library and User's Guide. Oxford Univ. Press, New York.

Draper, N., Smith, H., 1998. Applied Regression Analysis, 3rd ed. Wiley, New York.

Florinsky, I., Eilers, R., Manning, G., Fuller, L., 2002. Prediction of soil properties by digital terrain modelling. Environmental Modelling and Software 17, 295-311.

Gessler, P., Moore, I., McKenzie, N., Ryan, P., 1995. Soil-landscape modelling and spatial prediction of soil attributes. International Journal of Geographical Information Systems 9 (4), $421-432$.

Gobin, A., 2000. Participatory and spatial-modelling methods for land resources analysis. Phd thesis, Katholik Universiteit Leuven.

Gobin, A., Campling, P., Feyen, J., 2001. Soil-landscape modelling to quantify spatial variability of soil texture. Physics and Chemistry of the Earth. Part B: Hydrology, Oceans and Atmosphere 26 (1), 41-45.

Goovaerts, P., 1997. Geostatistics for Natural Resources Evaluation. Oxford Univ. Press, New York.

Goovaerts, P., 1999a. Geostatistics in soil science: state-of-the-art and perspectives. Geoderma 89 (1-2), 1-45.

Goovaerts, P., 1999b. Using elevation to aid the geostatistical mapping of rainfall erosivity. Catena 34 (3-4), 227-242.

Gotway, C., Stroup, W., 1997. A generalized linear model approach to spatial data analysis and prediction. Journal of Agricultural, Biological, and Environmental Statistics 2 (2), 157-198.

Hengl, T., Walvoort, D., Brown, A., 2002. Pixel (PM) and colour mixture (CM): GIS techniques for visualization of fuzziness and uncertainty of natural resource inventories. In: Hunter, G.J., Lowell, K. (Eds.), Proceedings of the 5th International Symposium on Spatial Accuracy Assessment in Natural Resources and Environmental Sciences (Accuracy 2002). RMIT University, Melbourne, pp. 300-309.

Hengl, T., Gruber, S., Shrestha, D., 2003a. Digital Terrain Analysis in ILWIS. Lecture notes, International Institute for Geo-Information Science and Earth Observation (ITC) Enschede. URL http://www.itc.nl/personal/shrestha/DTA/.

Hengl, T., Heuvelink, G., Stein, A., 2003b. Comparison of kriging with external drift and regression kriging. Technical report. International Institute for Geo-information Science and Earth 
Observation (ITC) Enschede. URL http://www.itc.nl/library/ Academic_output.

Heuvelink, G., Webster, R., 2001. Modelling soil variation; past, present and future. Geoderma 100, 269-301.

Hudson, G., Wackernagel, H., 1994. Mapping temperature using kriging with external drift: theory and an example from scotland. International Journal of Climatology 14 (1), 77-91.

Isaaks, E., Srivastava, R., 1989. Applied Geostatistics. Oxford Univ. Press, New York.

Jenny, H., 1980. The soil resource: origin and behavior, K. Clayton edition. Ecological Studies, vol. 37. Springer, NewYork.

Jiang, B., Kainz, W., Ormelling, F., 1995. A modified HLS system used in the visualization of uncertainty. International Symposium on RS, GIS and GPS in Sustainable Development of Environmental Monitoring. The Chinese University of Hong Kong, Hong Kong, pp. 701-712.

Kitanidis, P., 1994. Generalized covariance functions in estimation. Mathematical Geology 25, 525-540.

Knotters, M., Brus, D., Voshaar, J., 1995. A comparison of kriging, co-kriging and kriging combined with regression for spatial interpolation of horizon depth with censored observations. Geoderma 67 (3-4), 227-246.

Lane, P., 2002. Generalized linear models in soil science. European Journal of Soil Science 53, 241-251.

Looney, S., Gulledge Jr., T., 1985. Use of the correlation coefficient with normal probability plots. The American Statistician 39, $75-79$.

Martinović, J., Vranković, A., 1997. Croatian Soil Database (in Croatian), vol. 1. Ministry of Environmental Protection and Physical Planning, Zagreb, 325 pp.

Matheron, G., 1969. Le krigeage universel. Cachiers du Centre de Morphologie Mathematique, vol. 1. Ecole des Mines de Paris, Fontainebleau.

MathSoft, G., 1999. S-PLUS 4 Guide to Statistics. Vol. 1 and 2 MathSoft, Seattle.

McBratney, A., Walvoort, D., 2001. Generalised linear model kriging: a generic framework for kriging with secondary data. In: Meirvenne, M.V. (Ed.), 4th Conference of the Working Group on Pedometrics. University of Ghent, Ghent, Belgium.

McBratney, A., Webster, R., 1986. Choosing functions for semivariograms of soil properties and fitting them to sampling estimates. Journal of Soil Science 37, 617-639.

McBratney, A., Odeh, I., Bishop, T., Dunbar, M., Shatar, T., 2000. An overview of pedometric techniques of use in soil survey. Geoderma 97 (3-4), 293-327.

McBratney, A., Mendonça Santos, M., Minasny, B., 2003. On digital soil mapping. Geoderma 117, 3-52.

McKenzie, N., Ryan, P., 1999. Spatial prediction of soil properties using environmental correlation. Geoderma 89 (1-2), 67-94.
Minasny, B., McBratney, A., 2001. A rudimentary mechanistic model for soil formation and landscape development ii: a twodimensional model incorporating chemical weathering. Geoderma 103, 161-179.

Minasny, B., McBratney, A., Whelan, B., 2002. VESPER version 1.5. Australian Centre for Precision Agriculture, McMillan Building A05, The University of Sydney, NSW 2006. URL http://www.usyd.edu.au/su/agric/acpa.

Mitas, L., Mitasova, H., 1999. Spatial interpolation. In: Longley, P., Good-child, M., Maguire, D., Rhind, D., (Eds.), Geographical Information Systems: Principles, Techniques, Management and Applications, vol. 1. Wiley, London, pp. 481-492.

Moore, I., Gessler, P., Nielsen, G., Peterson, G., 1993. Soil attribute prediction using terrain analysis. Soil Science Society of America Journal 57 (2), $443-452$.

Neter, J., Kutner, M., Nachtsheim, C., Wasserman, W., (Eds.), 1996. Applied Linear Statistical Models, 4th ed. The McGraw-Hill, p. 1408.

Odeh, I., McBratney, A., Chittleborough, D., 1994. Spatial prediction of soil properties from landform attributes derived from a digital elevation model. Geoderma 63 (3-4), 197-214.

Odeh, I., McBratney, A., Chittleborough, D., 1995. Further results on prediction of soil properties from terrain attributes: heterotopic cokriging and regression-kriging. Geoderma 67 (3-4), $215-226$.

Opsomer, J., Ruppert, D., Wand, M., Holst, U., Hössjer, O., 1999. Kriging with nonparametric variance function estimation. Biometrics 55 (3), 704-710.

Ott, R., Longnecker, M. (Eds.), 2001. An Introduction to Statistical Methods and Data Analysis, 5th ed. Duxbury Press, p. 1152.

Papritz, A., Stein, A., 1999. Spatial prediction by linear kriging. In: Stein, A., van der Meer, F., Gorte, B. (Eds.), Spatial Statistics for Remote Sensing. Kluwer Academic Publishing, Dodrecht, pp. 83-113.

Park, S., Vlek, P., 2002. Environmental correlation of three-dimensional soil spatial variability: a comparison of three adaptive techniques. Geoderma 109 (1-2), 117-140.

Pebesma, E., 2003. Gstat: multivariable geostatistics for s. Distributed Statistical Computing, working papers. Vienna, Austria, pp. 1-11. URL http://www.ci.tuwien.ac.at/Conferences/ DSC-2003/.

Triantafilis, J., Ward, W., McBratney, A., 2001. Land suitability assessment in the namoi valley of australia, using a continuous model. Australian Journal of Soil Research 39, 273-290.

Unit Geo Software Development, 2001. ILWIS 3.0 Academic user's guide. ITC, Enschede. URL http://www.itc.nl/ilwis/.

Wackernagel, H., 1998. Multivariate Geostatistics: An Introduction With Applications, 2nd ed. Springer, Berlin. 